\title{
Awareness of Images of Women Aged 20-50 Years and Sense of Self-effectiveness through Production of Hair Images
}

\author{
Man-suk Han ${ }^{1}$, Young-Sam Kim ${ }^{2 *}$ \\ ${ }^{1}$ Department of Cosmetics Engineering, Konkuk University, Seoul, Korea \\ ${ }^{2}$ Department of Image Industry, Graduate School of Engineering, Konkuk University, Seoul, Korea
}

\begin{abstract}
"Corresponding author: Young-Sam Kim, Department of Image Industry, Graduate School of Engineering, Konkuk University, 120 Neungdong-ro, Gwangjin-gu, Seoul 05029, Korea
\end{abstract}

Tel.: +82 24503595

Email: gracehelen@konkuk.ac.kr

This work is part of the Man-suk Han's M.Sc. thesis at the Konkuk University, Seoul, Korea

Received October 31, 2019

Revised December 13, 2019

Accepted December 24, 2019

Published December 30, 2019

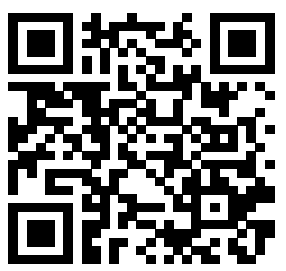

\begin{abstract}
Purpose: It is becoming increasingly recognized that image plays an important role as a social and relational means, and managing self-image greatly influences interpersonal relationships and social lives. Accordingly, this study aimed to enhance self-efficacy and create a positive favorable image through an appropriate image and hairstyle. Methods: A questionnaire survey was conducted on 385 women living in the Gyeonggi Province. The collected data were analyzed using the SPSS WIN 25.0 program, frequency and percentage, $x^{2}$-test, $t$-test, and One-way ANOVA were conducted. Result: The results showed that there is no significant difference in women's interest in image and image change factors in general characteristics, and most of the women need managing image. The main causes of image formation were language, followed by hair style, clothing, and makeup, and of these, the main reason for changing the hairstyle was to improve the image. When the hair image was well displayed, the overall average was 3.82 out of 5, indicating a high level of self-efficacy. Conclusion: It is expected that this study will provide basic data that can be used as an indicator in the selection and displaying of the image suitable for the situation and also used diversely as a psychological mediator that can enhance individual self-efficacy.
\end{abstract}

Keywords: Hair image, Image preference, Self-efficacy, Hair production, Image change factor

\section{Introduction}

현대에는 기업의 브랜드 이미지뿐만 아니라 개인의 자기이미지 관리의 중요성이 두드러지면서 이미지, 루키즘, 외모지상주의 등 의 문화를 수용함에 따라 첫인상과 외적인 것을 더욱 중요시하게 되었고(Park, 2018), 개인이 자기이미지를 통해 평가받게 됨에 따라 자기이미지 형성 및 관리에 관심이 증대되었다. 자기이미지 는 상대방이 자신에게 얻는 정보를 종합적으로 조합하여 주관적 으로 분석 판단되기 때문에, 타인에게 긍정적인 호감을 주거나 상 황이나 관계에 필요로 하고 원하는 이미지를 형성하고 관리가 매 우 중요하다. 특히, 이미지가 사회적, 관계적 주요 수단으로 역할 을 함에 따라 외적인 모습을 통하여 타인의 평가 기준인 이미지를 형성하기 때문에, 대인 관계 및 사회생활에 중요한 영향을 미친다
는 인식이 높아지고 있다(Hassin \& Trope, 2000). 또한, 오늘날 여성들의 자기이미지 형성은 간단하게 헤어스타일을 연출하고 화 장을 하며, 의복을 결정하는 차원에서 벗어나 전체적인 조화를 이 루도록 하여 자기효능감을 높이고 긍정적인 호감의 이미지를 창 출이 필요한 실정이다.

헤어스타일은 외모를 통한 이미지형성 중에서 개인의 첫인상과 분위기를 좌우할 수 있는 중요한 수단이다(Kaiser, 1990). 개인 의 연령, 성격, 감정, 상황, 역할 등 개인만의 개성을 나타내는 수 단으로 얼굴 이미지에 큰 요인이고, 얼굴과 함께 눈으로 볼 수 있 는 요인 중 큰 비중을 차지한다(Feingold, 1992). 즉, 헤어이미 지 연출은 외모에 자신감을 얻는 것을 넘어서 자신의 능력을 표출 하고 사회적, 관계적 이미지 향상의 도구로 활용되고 있으며 이로 인하여 개인의 자기이미지 형성과 자기효능감에 영향을 미칠 수 
있다.

최근 신체이미지가 연봉(Hamermesh \& Biddle, 1994), 대인 관계(Cha, 2015)에 미치는 영향 얼굴이미지가 직무만족(Kim, 2018)에 미치는 영향 자기이미지가(Hong \& Kim, 2017)가 패 션에 미치는 영향 이미지메이킹이 메이킹효능감(Moon et al., 2015)에 미치는 영향 조사는 있었지만 헤어이미지와 연관하여 분 석한 자기효능감을 나타내기에는 역부족이다.

이에 본 연구에서는 현재 수도권 지역의 사회활동의 주 연령대 인 20-50대 여성의 이미지에 대한 인식과 헤어이미지 연출이 자 기효능감에 미치는 영향을 분석하고자 한다.

따라서 본 연구는 시대적 흐름이 요구하는 적합한 이미지 연출
및 선택에 있어서 지표가 될 수 있는 기초 자료를 제공하고 나아 가 이러한 이미지 연출이 이미지 메이킹의 한 분야뿐 아니라 개인 의 자기효능감을 높일 수 있는 심리적 매개 요인으로써의 자료를 제공하는데, 그 목적이 있다.

\section{Methods}

\section{1. 연구참여자 및 기간}

본 연구는 경기도 지역에 거주하는 20-50대 여성을 대상으로 2018년 9월 3일부터 9월 29일까지 28일 동안 설문을 설명한 설

Table 1. General characteristics of study participants

\begin{tabular}{|c|c|c|c|}
\hline & Sortation & Frequency (order) & Percentage (\%) \\
\hline \multirow{5}{*}{ Age } & $20-27 s$ & 76 & 19.7 \\
\hline & $28-35 s$ & 78 & 20.3 \\
\hline & $36-43 s$ & 116 & 30.1 \\
\hline & $44-51 s$ & 58 & 15.1 \\
\hline & $52-59 s$ & 57 & 14.8 \\
\hline \multirow{2}{*}{ Marital status } & Single & 130 & 33.8 \\
\hline & Married & 255 & 66.2 \\
\hline \multirow{7}{*}{ Occupation } & Professional & 73 & 19.0 \\
\hline & Education & 54 & 14.0 \\
\hline & Sale/service & 56 & 14.5 \\
\hline & Art, design related position & 23 & 6.0 \\
\hline & Housewife & 83 & 21.6 \\
\hline & Office worker/civil servant & 55 & 14.3 \\
\hline & Other & 41 & 10.6 \\
\hline \multirow{4}{*}{ Final education } & High school graduation & 59 & 15.3 \\
\hline & In college & 26 & 6.8 \\
\hline & College graduate & 213 & 55.3 \\
\hline & Graduate school and above & 87 & 22.6 \\
\hline \multirow{6}{*}{ Average monthly income } & Under $2,000,000$ won & 143 & 37.1 \\
\hline & $2,000,000-2,990,000$ won & 132 & 34.3 \\
\hline & $3,000,000-3,990,000$ won & 57 & 14.8 \\
\hline & $4,000,000-4,990,000$ won & 29 & 7.5 \\
\hline & Above $5,000,000$ won & 24 & 6.2 \\
\hline & Total & 385 & 100.0 \\
\hline
\end{tabular}

Table 2. Measuring tool

\begin{tabular}{llcc}
\hline & Sortation & Frequency (order) & Percentage (\%) \\
\cline { 2 - 3 } Self-efficacy & Psychological efficacy & 5 & 0.82 \\
& Confidence & 5 & 0.83 \\
& Social effectiveness & 5 & 0.86 \\
& Overall self-efficacy & 15 & 0.91 \\
\hline
\end{tabular}


문지를 통해 자기 기입식 설문조사 방식으로 조사하였으며, 총 421 부를 배부하였으며, 그 중 응답이 정확하지 않은 36 부를 제외 한 설문지 총 385 부를 최종 분석 자료로 사용하였다.

\section{2. 자료분석}

수집된 자료는 SPSS WIN 25.0 프로그램을 이용하여 분석하였 다. 분석기법으로는 연구 참여자의 일반적 특성을 살펴보기 위해

Table 3. Image management necessity

\begin{tabular}{|c|c|c|c|c|c|c|}
\hline & Sortation & Yes & No & Total & $x^{2}(d f)$ & $p$ \\
\hline \multirow{5}{*}{ Age } & $20-27 s$ & $76(100.0)$ & $0(0.0)$ & $76(19.7)$ & \multirow{5}{*}{$7.91(4)$} & \multirow{5}{*}{0.095} \\
\hline & $28-35 s$ & $76(97.4)$ & $2(2.6)$ & $78(20.3)$ & & \\
\hline & $36-43 s$ & $116(100.0)$ & $0(0.0)$ & $116(30.1)$ & & \\
\hline & $44-51 \mathrm{~s}$ & $58(100.0)$ & $0(0.0)$ & $58(15.1)$ & & \\
\hline & $52-59 s$ & $57(100.0)$ & $0(0.0)$ & $57(14.8)$ & & \\
\hline \multirow{11}{*}{ Marital status } & Single & $129(99.2)$ & $1(0.8)$ & $130(33.8)$ & \multirow{2}{*}{$0.24(1)$} & \multirow{2}{*}{0.626} \\
\hline & Married & 254 (99.6) & $1(0.4)$ & $255(66.2)$ & & \\
\hline & Professional & $72(98.6)$ & $1(1.4)$ & 73 (19.0) & \multirow{6}{*}{$3.15(5)$} & \multirow{6}{*}{0.676} \\
\hline & $\begin{array}{l}\text { Education/art, design } \\
\text { related position }\end{array}$ & $76(98.7)$ & $1(1.3)$ & $77(20.0)$ & & \\
\hline & Sale/service & $56(100.0)$ & $0(0.0)$ & $56(14.5)$ & & \\
\hline & Housewife & $83(100.0)$ & $0(0.0)$ & $83(21.6)$ & & \\
\hline & Office worker/civil servant & 55 (100.0) & $0(0.0)$ & $55(14.3)$ & & \\
\hline & Other & $41(100.0)$ & $0(0.0)$ & $41(10.6)$ & & \\
\hline & High school graduation & 59 (100.0) & $0(0.0)$ & $59(15.3)$ & \multirow{3}{*}{$1.02(2)$} & \multirow{3}{*}{0.599} \\
\hline & In college/college graduate & 238 (99.6) & $1(0.4)$ & $239(62.1)$ & & \\
\hline & Graduate school and above & $86(98.9)$ & $1(1.1)$ & $87(22.6)$ & & \\
\hline Total & & 383 (99.5) & $2(0.5)$ & 385 (100.0) & & \\
\hline
\end{tabular}

Table. 4 Image formation critical element

\begin{tabular}{|c|c|c|c|c|c|c|c|c|c|}
\hline & Sortation & Language & Behavior & Hair style & Make up & Clothing & Total & $x^{2}(d f)$ & $p$ \\
\hline \multirow{5}{*}{ Age } & $20-27 s$ & $16(21.1)$ & $20(26.3)$ & 18 (23.7) & $8(10.5)$ & 14 (18.4) & 76 (19.7) & \multirow{5}{*}{$\begin{array}{c}40.23^{* *} \\
(16)\end{array}$} & \multirow{5}{*}{0.001} \\
\hline & $28-35 s$ & 28 (35.9) & 23 (29.5) & 9 (11.5) & $3(3.8)$ & 15 (19.2) & 78 (20.3) & & \\
\hline & $36-43 s$ & $54(46.6)$ & 32 (27.6) & $13(11.2)$ & $6(5.2)$ & $11(9.5)$ & $116(30.1)$ & & \\
\hline & $44-51 s$ & $21(36.2)$ & $8(13.8)$ & 17 (29.3) & $1(1.7)$ & 11 (19.0) & 58 (15.1) & & \\
\hline & $52-59 s$ & 18 (31.6) & $17(29.8)$ & $16(28.1)$ & $0(0.0)$ & $6(10.5)$ & 57 (14.8) & & \\
\hline \multirow{2}{*}{$\begin{array}{l}\text { Marital } \\
\text { status }\end{array}$} & Single & 40 (30.8) & 31 (23.8) & $23(17.7)$ & $11(8.5)$ & 25 (19.2) & 130 (33.8) & \multirow{2}{*}{$10.40^{*}(4)$} & \multirow{2}{*}{0.034} \\
\hline & Married & $97(38.0)$ & 69 (27.1) & 50 (19.6) & $7(2.7)$ & 32 (12.5) & 255 (66.2) & & \\
\hline \multirow{6}{*}{$\begin{array}{l}\text { Occup } \\
\text { ation }\end{array}$} & Professional & 23 (31.5) & $22(30.1)$ & $16(21.9)$ & $3(4.1)$ & $9(12.3)$ & 73 (19.0) & \multirow{6}{*}{$16.01(2)$} & \multirow{6}{*}{0.716} \\
\hline & $\begin{array}{l}\text { Education/art, design } \\
\text { related position }\end{array}$ & 35 (45.5) & $18(23.4)$ & $13(16.9)$ & $2(2.6)$ & $9(11.7)$ & 77 (20.0) & & \\
\hline & Sale/service & $14(25.0)$ & $13(23.2)$ & $12(21.4)$ & $3(5.4)$ & $14(25.0)$ & 56 (14.5) & & \\
\hline & Housewife & $28(33.7)$ & 25 (30.1) & $14(16.9)$ & $4(4.8)$ & 12 (14.5) & 83 (21.6) & & \\
\hline & $\begin{array}{l}\text { Office worker/civil } \\
\text { servant }\end{array}$ & $21(38.2)$ & $12(21.8)$ & $12(21.8)$ & $2(3.6)$ & $8(14.5)$ & 55 (14.3) & & \\
\hline & Other & 16 (39.0) & $10(24.4)$ & $6(14.6)$ & $4(9.8)$ & $5(12.2)$ & 41 (10.6) & & \\
\hline \multirow{3}{*}{$\begin{array}{l}\text { Final } \\
\text { educa } \\
\text { tion }\end{array}$} & $\begin{array}{l}\text { High school } \\
\text { graduation }\end{array}$ & 20 (33.9) & $15(25.4)$ & $14(23.7)$ & $2(3.4)$ & $8(13.6)$ & 59 (15.3) & \multirow{3}{*}{$7.72(8)$} & \multirow{3}{*}{0.462} \\
\hline & $\begin{array}{l}\text { In college/college } \\
\text { graduate }\end{array}$ & 78 (32.6) & $65(27.2)$ & 42 (17.6) & $13(5.4)$ & 41 (17.2) & 239 (62.1) & & \\
\hline & $\begin{array}{l}\text { Graduate school and } \\
\text { above }\end{array}$ & 39 (44.8) & $20(23.0)$ & $17(19.5)$ & $3(3.4)$ & $8(9.2)$ & 87 (22.6) & & \\
\hline Total & & 137 (35.6) & $100(26.0)$ & 73 (19.0) & $18(4.7)$ & $57(14.8)$ & 38 (100.0) & & \\
\hline
\end{tabular}

${ }^{*} p<0.05 ;{ }^{* *} p<0.01$. 
빈도와 백분율을 구하였다. 여성들의 이미지에 대한 인식과 헤어이 미지 연출에 따른 자기효능감을 알아보기 위해 $t$-test 와 $\chi^{2}(\mathrm{Chi}-$ square)-test 그리고 one-way ANOVA(일원변량분석)를 실시하 였다.

\section{Results and Discussion}

\section{1. 연구 참여자의 일반적 특성}

본 연구의 연구 참여자의 일반적 특성은 Table 1 과 같다.

총 385명 중 연령 별로는 36-43세가 $30.1 \%$ 로 가장 많게 나타 났으며, 결혼 여부 특성 별로는 기혼이 $66.2 \%$ 로 미혼 $3.38 \%$ 보다 높은 분포를 보였다. 직업별로는 주부가 $21.6 \%$ 로 가장 많게 나타 났으며, 다음으로 전문직 $19.0 \%$, 판매/서비스 $14.5 \%$, 일반 사무 직/공무원 $14.3 \%$, 교육직 $14.0 \%$, 기타 $10.6 \%$, 예술, 디자인 관 련직 $6.0 \%$ 순으로 나타났다. 최종학력별로는 대졸이 $55.3 \%$ 로 절 반 이상을 차지하였으며, 월평균 소득 특성 별로는 200 만원이 $37.1 \%$ 로 가장 많게 나타났으며, 다음으로 200-299만원 34.3\%, $300-399$ 만원 14.8\%, 400-499만원 7.5\%, 500만원 이상 $6.2 \%$ 순으로 나타났다.

\section{2. 측정 도구의 신뢰도 검증}

Table 5. Top reasons for changes in hair styles

\begin{tabular}{|c|c|c|c|c|c|c|c|c|}
\hline & Sortation & $\begin{array}{c}\text { To gain } \\
\text { confidence in } \\
\text { one's features }\end{array}$ & $\begin{array}{l}\text { To improve the } \\
\text { image }\end{array}$ & $\begin{array}{l}\text { For smooth } \\
\text { interpersonal } \\
\text { relationship }\end{array}$ & $\begin{array}{l}\text { Because } \\
\text { others do it }\end{array}$ & Total & $x^{2}(d f)$ & $p$ \\
\hline \multirow{5}{*}{ Marital status } & $20-27 s$ & $31(40.8)$ & 39 (51.3) & $3(3.9)$ & $3(3.9)$ & 76 (19.7) & \multirow{5}{*}{$\begin{array}{l}44.62^{* * *} \\
(12)\end{array}$} & \multirow{5}{*}{0.000} \\
\hline & $28-35 s$ & 32 (41.0) & $40(51.3)$ & $4(5.1)$ & $2(2.6)$ & $78(20.3)$ & & \\
\hline & $36-43 s$ & $56(48.3)$ & $54(46.6)$ & $5(4.3)$ & $1(0.9)$ & $116(30.1)$ & & \\
\hline & $44-51 \mathrm{~s}$ & 25 (43.1) & $28(48.3)$ & $3(5.2)$ & $2(3.4)$ & 58 (15.1) & & \\
\hline & $52-59 s$ & 19 (33.3) & 19 (33.3) & $17(29.8)$ & $2(3.5)$ & $57(14.8)$ & & \\
\hline \multirow{2}{*}{ Marital status } & Single & $50(38.5)$ & $66(50.8)$ & $10(7.7)$ & $4(3.1)$ & $130(33.8)$ & \multirow{2}{*}{$1.64(3)$} & \multirow{2}{*}{0.651} \\
\hline & Married & $113(44.3)$ & $114(44.7)$ & $22(8.6)$ & $6(2.4)$ & $255(66.2)$ & & \\
\hline \multirow{6}{*}{ Occupation } & Professional & $28(38.4)$ & 38 (52.1) & $6(8.2)$ & $1(1.4)$ & 73 (19.0) & \multirow{6}{*}{13.06 (15) } & \multirow{6}{*}{0.598} \\
\hline & $\begin{array}{l}\text { Education/art, design } \\
\text { related position }\end{array}$ & 31 (40.3) & 34 (44.2) & $9(11.7)$ & $3(3.9)$ & $77(20.0)$ & & \\
\hline & Sale/service & $21(37.5)$ & $26(46.4)$ & 7 (12.5) & $2(3.6)$ & $56(14.5)$ & & \\
\hline & Housewife & 37 (44.6) & 37 (44.6) & $6(7.2)$ & $3(3.6)$ & $83(21.6)$ & & \\
\hline & $\begin{array}{l}\text { Office worker/civil } \\
\text { servant }\end{array}$ & $31(56.4)$ & $23(41.8)$ & $1(1.8)$ & $0(0.0)$ & 55 (14.3) & & \\
\hline & Other & 15 (36.6) & $22(53.7)$ & $3(7.3)$ & $1(2.4)$ & 41 (10.6) & & \\
\hline \multirow{3}{*}{$\begin{array}{l}\text { Final } \\
\text { education }\end{array}$} & $\begin{array}{l}\text { High school } \\
\text { graduation }\end{array}$ & $26(44.1)$ & 21 (35.6) & $9(15.3)$ & $3(5.1)$ & $59(15.3)$ & \multirow{3}{*}{$10.01(6)$} & \multirow{3}{*}{0.124} \\
\hline & $\begin{array}{l}\text { In college/college } \\
\text { graduate }\end{array}$ & 105 (43.9) & $115(48.1)$ & $14(5.9)$ & $5(2.1)$ & 239 (62.1) & & \\
\hline & $\begin{array}{l}\text { Graduate school and } \\
\text { above }\end{array}$ & $32(36.8)$ & $44(50.6)$ & $9(10.3)$ & $2(2.3)$ & $87(22.6)$ & & \\
\hline Total & & $163(42.3)$ & $180(46.8)$ & $32(8.3)$ & $10(2.6)$ & 385 (100.0) & & \\
\hline
\end{tabular}

${ }^{* * *} p<0.001$
본 연구의 측정 도구의 신뢰도를 검증한 결과는 Table 2 와 같으 며, Cronbach $\alpha$ 가 심리적 효과성 0.82 , 자신감 0.83 , 사회적 효 과성 0.86 , 자기효능감 0.91 로, 모두 0.80 이상으로 나타났다. 따 라서 본 연구의 측정 도구는 신뢰할 만한 수준임을 알 수 있다.

1)이미지 관리 필요성

이미지 관리 필요성에 대해 여성들의 인식을 살펴본 결과 는 Table 3 과 같이 이미지 관리가 필요하다고 인식하는 여성이 $99.5 \%$ 로 대부분을 차지하였으며, 그렇지 않다고 인식하는 여성은 $0.5 \%$ 로 매우 적은 것으로 나타났다. 이는 이미지 메이킹 교육의 필요성(Jin \& Kim, 2013)에 관한 연구에서 나타난 93.0\%보다높 은 수치로 이미지 필요성에 대한 인식이 높아졌다고 볼 수 있다.

Table 3 에서 보는 바와 같이 연령과 결혼여부, 직업, 최종학력, 그리고 월평균 소득의 일반적 특성별로는 큰 차이 없이 대부분의 여성이 이미지 관리가 필요하다고 인식하고 있음을 알 수 있다.

\section{2) 이미지 형성 중요요소}

이미지 형성 중요요소에 대해 여성들의 인식을 살펴본 결과는 Table 4와 같이 이미지 형성에 언어가 중요하다고 인식하는 여성 이 $35.6 \%$ 로 가장 많게 나타났으며, 다음으로 행동 $26.0 \%$, 헤어스 타일 $19.0 \%$, 의복 $14.8 \%$, 메이크업 $4.7 \%$ 순으로 나타났다. 이는

\section{3. 이미지에 대한 인식}


Cho \& Yang (2017)의 연구에서는 메이크업 $48.6 \%$, 헤어스타일 $24.2 \%$, 의복 $16.9 \%$, 피부 $10.3 \%$ 순으로 다르게 조사되었다.

여성들은 이미지 형성에 언어가 가장 중요하다고 인식하였으

며, 연령이 36-43세인 여성과 기혼인 여성이 다른 여성보다 이미
지 형성에 언어가 더 중요하다고 인식하였다.

이는 외모에 치중되어 있던 이미지 형성요인이 나이와 결혼 여 부에 따라 내적인 이미지를 나타내는 언어의 중요도가 점점 높게 인식되는 결과라 볼 수 있다.

Table 6. Psychological effectiveness

\begin{tabular}{|c|c|c|c|c|c|c|}
\hline & Sortation & $\mathrm{N}$ & Mean & SD & For $t$ & $p$ \\
\hline \multirow{5}{*}{ Age } & $20-27 s$ & 76 & 4.03 & 0.60 & \multirow{5}{*}{2.13} & \multirow{5}{*}{0.077} \\
\hline & $28-35 s$ & 78 & 4.15 & 0.60 & & \\
\hline & $36-43 s$ & 116 & 4.16 & 0.65 & & \\
\hline & $44-51 s$ & 58 & 4.14 & 0.59 & & \\
\hline & $52-59 s$ & 57 & 3.89 & 0.70 & & \\
\hline \multirow{2}{*}{ Marital status } & Single & 130 & 4.03 & 0.61 & \multirow{2}{*}{-1.36} & \multirow{2}{*}{0.175} \\
\hline & Married & 255 & 4.12 & 0.64 & & \\
\hline \multirow{6}{*}{ Occupation } & Professional & 73 & 4.18 & 0.58 & \multirow{6}{*}{1.34} & \multirow{6}{*}{0.246} \\
\hline & $\begin{array}{l}\text { Education/art, design } \\
\text { related position }\end{array}$ & 77 & 4.16 & 0.57 & & \\
\hline & Sale/service & 56 & 3.95 & 0.74 & & \\
\hline & Housewife & 83 & 4.02 & 0.67 & & \\
\hline & Office worker/civil servant & 55 & 4.13 & 0.65 & & \\
\hline & Other & 41 & 4.05 & 0.58 & & \\
\hline \multirow{3}{*}{ Final education } & High school graduation & 59 & 3.91 & 0.73 & \multirow{3}{*}{$6.69^{* *}$} & \multirow{3}{*}{0.001} \\
\hline & In college/college graduate & 239 & 4.07 & 0.61 & & \\
\hline & Graduate school and above & 87 & 4.28 & 0.58 & & \\
\hline Total & & 385 & 4.09 & 0.64 & & \\
\hline
\end{tabular}

${ }^{* *} p<0.01$.

Table 7. Confidence

\begin{tabular}{|c|c|c|c|c|c|c|}
\hline & Sortation & $\mathrm{N}$ & Mean & $\mathrm{SD}$ & For $t$ & $p$ \\
\hline \multirow{5}{*}{ Age } & $20-27 s$ & 76 & 3.79 & 0.62 & \multirow{5}{*}{2.34} & \multirow{5}{*}{0.054} \\
\hline & $28-35 s$ & 78 & 3.75 & 0.75 & & \\
\hline & $36-43 s$ & 116 & 3.93 & 0.68 & & \\
\hline & $44-51 s$ & 58 & 4.06 & 0.59 & & \\
\hline & $52-59 s$ & 57 & 3.88 & 0.57 & & \\
\hline \multirow{2}{*}{ Marital status } & Single & 130 & 3.76 & 0.65 & \multirow{2}{*}{$-2.52^{*}$} & \multirow{2}{*}{0.012} \\
\hline & Married & 255 & 3.94 & 0.66 & & \\
\hline \multirow{6}{*}{ Occupation } & Professional & 73 & 3.94 & 0.67 & \multirow{6}{*}{0.81} & \multirow{6}{*}{0.544} \\
\hline & $\begin{array}{l}\text { Education/art, design } \\
\text { related position }\end{array}$ & 77 & 3.93 & 0.64 & & \\
\hline & Sale/service & 56 & 3.91 & 0.75 & & \\
\hline & Housewife & 83 & 3.86 & 0.65 & & \\
\hline & Office worker/civil servant & 55 & 3.85 & 0.60 & & \\
\hline & Other & 41 & 3.71 & 0.64 & & \\
\hline \multirow{3}{*}{ Final education } & High school graduation & 59 & 3.81 & 0.72 & \multirow{3}{*}{1.31} & \multirow{3}{*}{0.270} \\
\hline & In college/college graduate & 239 & 3.86 & 0.66 & & \\
\hline & Graduate school and above & 87 & 3.97 & 0.61 & & \\
\hline Total & & 385 & 3.88 & 0.66 & & \\
\hline
\end{tabular}


3) 헤어스타일 변화 주요 이유

여성들이 헤어스타일을 변화시키는 주된 이유에 대해 분석한 결과는 Table 5 와 같이 헤어스타일을 이미지 개선을 위해 변화시
키는 여성이 $46.8 \%$ 로 가장 많게 나타났으며, 다음으로 용모에 자 신감을 얻기 위해서 $42.3 \%$, 원활한 대인관계를 위해서 $8.3 \%$, 다 른 사람들도 다 하니까 $2.6 \%$ 순으로 나타났다.

헤어스타일을 이미지 개선을 위해 변화시키는 여성이 가장 많

Table 8. Social effectiveness

\begin{tabular}{|c|c|c|c|c|c|c|}
\hline & Sortation & $\mathrm{N}$ & Mean & SD & For $t$ & $p$ \\
\hline \multirow{5}{*}{ Age } & $20-27 s$ & 76 & 3.53 & 0.72 & \multirow{5}{*}{1.47} & \multirow{5}{*}{0.212} \\
\hline & $28-35 s$ & 78 & 3.37 & 0.80 & & \\
\hline & $36-43 s$ & 116 & 3.45 & 0.86 & & \\
\hline & $44-51 s$ & 58 & 3.64 & 0.76 & & \\
\hline & $52-59 s$ & 57 & 3.61 & 0.58 & & \\
\hline \multirow{2}{*}{ Marital status } & Single & 130 & 3.43 & 0.77 & \multirow{2}{*}{-1.32} & \multirow{2}{*}{0.187} \\
\hline & Married & 255 & 3.54 & 0.77 & & \\
\hline \multirow{6}{*}{ Occupation } & Professional & 73 & 3.52 & 0.84 & \multirow{6}{*}{1.36} & \multirow{6}{*}{0.239} \\
\hline & $\begin{array}{l}\text { Education/art, design } \\
\text { related position }\end{array}$ & 77 & 3.68 & 0.66 & & \\
\hline & Sale/service & 56 & 3.50 & 0.76 & & \\
\hline & Housewife & 83 & 3.41 & 0.77 & & \\
\hline & Office worker/civil servant & 55 & 3.49 & 0.82 & & \\
\hline & Other & 41 & 3.36 & 0.76 & & \\
\hline \multirow{3}{*}{ Final education } & High school graduation & 59 & 3.42 & 0.82 & \multirow{3}{*}{1.67} & \multirow{3}{*}{0.190} \\
\hline & In college/college graduate & 239 & 3.48 & 0.76 & & \\
\hline & Graduate school and above & 87 & 3.63 & 0.77 & & \\
\hline Total & & 385 & 3.50 & 0.77 & & \\
\hline
\end{tabular}

Table 9. Self-efficacy

\begin{tabular}{|c|c|c|c|c|c|c|}
\hline & Sortation & $\mathrm{N}$ & Mean & SD & Fort & $p$ \\
\hline \multirow{5}{*}{ Age } & $20-27 s$ & 76 & 3.79 & 0.55 & \multirow{5}{*}{1.03} & \multirow{5}{*}{0.390} \\
\hline & $28-35 s$ & 78 & 3.76 & 0.63 & & \\
\hline & $36-43 s$ & 116 & 3.85 & 0.64 & & \\
\hline & $44-51 s$ & 58 & 3.95 & 0.54 & & \\
\hline & $52-59 s$ & 57 & 3.80 & 0.48 & & \\
\hline \multirow{2}{*}{ Marital status } & Single & 130 & 3.74 & 0.58 & \multirow{2}{*}{$-2.01^{*}$} & \multirow{2}{*}{0.046} \\
\hline & Married & 255 & 3.87 & 0.59 & & \\
\hline \multirow{6}{*}{ Occupation } & Professional & 73 & 3.88 & 0.59 & \multirow{6}{*}{1.11} & \multirow{6}{*}{0.352} \\
\hline & $\begin{array}{l}\text { Education/art, design } \\
\text { related position }\end{array}$ & 77 & 3.92 & 0.51 & & \\
\hline & Sale/service & 56 & 3.79 & 0.68 & & \\
\hline & Housewife & 83 & 3.76 & 0.58 & & \\
\hline & Office worker/civil servant & 55 & 3.82 & 0.60 & & \\
\hline & Other & 41 & 3.71 & 0.57 & & \\
\hline \multirow{3}{*}{ Final education } & High school graduation & 59 & 3.71 & 0.67 & \multirow{3}{*}{$3.68^{*}$} & \multirow{3}{*}{0.026} \\
\hline & In college/college graduate & 239 & 3.80 & 0.57 & & \\
\hline & Graduate school and above & 87 & 3.96 & 0.55 & & \\
\hline Total & & 385 & 3.82 & 0.59 & & \\
\hline
\end{tabular}


았으며, 35 세 이하인 여성이 다른 연령대 여성보다 헤어스타일 을 이미지 개선을 위해 변화시켰다.

\section{2. 자기효능감}

\section{1) 심리적 효과성}

여성들이 헤어 연출이 잘 되었을 때의 심리적 효과성에 대해 분석한 결과는 Table 6 과 같이 5 점 만점 중 전체 평균이 4.09 로, 여성들은 심리적 효과성이 매우 높은 것으로 나타났다.

여성들이 헤어 연출이 잘 되었을 때의 심리적 효과성이 매우 높았으며, 최종학력이 높은 여성일수록 다른 여성보다 심리적 효과성이 더 높았다.

\section{2) 자신감}

여성들이 헤어 연출이 잘 되었을 때의 심리적 효과성에 대해 분석한 결과는 Table 6 과 같이 5점 만점 중 전체 평균이 4.09 로, 여성들은 심리적 효과성이 매우 높은 것으로 나타났다.

여성들은 자신감이 높았으며, 기혼인 여성이 미혼인 여성보 다 자신감이 더 높았다.

\section{3) 사회적 효과성}

여성들이 헤어 연출이 잘 되었을 때의 사회적 효과성에 대해 분석한 결과는 Table 8 과 같이 5 점 만점 중 전체 평균이 3.50 으로, 여성들은 사회적 효과성이 높은 것으로 나타났다.

여성들이 헤어 연출이 잘 되었을 때의 사회적 효과성이 높았 으며, 연령과 결혼 여부, 직업, 최종학력, 그리고 월평균 소득 특 성 별로는 별다른 차이가 없었다.

\section{4) 자기효능감}

여성들이 헤어 연출이 잘 되었을 때의 자기효능감에 대해 분 석한 결과는 Table 9 와 같이 5점 만점 중 전체 평균이 3.82 로, 여성들은 자기효능감이 높은 것으로 나타났다.

여성들이 헤어 연출이 잘 되었을 때의 자기효능감이 높았으 며, 이는 $\operatorname{Kim}$ (2018)의 연구에서 이미지가 직무에 긍정적인 영 향을 미치는 것과 같았다. 또한, 기혼인 여성과 최종학력이 높은 여성일수록 다른 여성보다 자기효능감이 더 높았다.

\section{Conclusion}

이미지가 사회적, 관계적 주요 수단으로서 역할을 하고 자 기 이미지 관리가 대인 관계 및 사회생활에 큰 영향을 미친다 는 인식이 높아지고 있다. 이에 상황에 맞는 이미지와 헤어스 타일을 통하여 자기효능감을 높이고 긍정적인 호감의 이미지 창출이 필요하다는 인식에서 본 연구를 시작하였다. 이를 위해
사회활동의 주 연령대인 20-50대 여성의 이미지에 대한 인식 과 헤어이미지 연출이 자기효능감에 미치는 영향을 분석하였 다. 경기도에 거주하는 20-50대 여성 385명을 대상으로 인터 넷 설문을 시행하여 수집된 자료는 SPSS WIN 25.0 프로그램 을 이용하여 분석하였다. 연구 참여자의 일반적 특성을 살펴보 기 위해 빈도와 백분율을, 여성들의 이미지에 대한 인식과 연출 에 따른 자기효능감을 알아보기 위해 $\chi^{2}$-test, $t$-test, 그리 고 one-way ANOVA를 실시하였으며, 그 결과는 다음과 같다. 첫째, 여성들의 이미지 관심도와 이미지 변화요인을 조사한 결 과 일반적 특성별로는 큰 차이 없이 여성 대부분이 이미지 관리 가 필요하며, 이미지 형성의 주요 원인은 언어, 헤어스타일, 의 복, 메이크업 순으로 나타났고, 이 중 헤어스타일의 변화시키 는 주된 요인은 이미지 개선을 위한 것이었다. 둘째, 헤어이미 지 연출이 잘 되었을 때 자기효능감은 5 점 만점에 심리적 효과 성 평균 4.09 , 자신감 평균 3.88 , 사회적 효과성 3.50 으로 헤 어이미지 연출이 잘 되었을 때 5 점 만점 중 전체 평균이 3.82 로, 자기효능감이 높은 것으로 나타났다. 신체적 이미지가 자 기효능감에 미치는 영향을 대학생(Kim \& Cho, 2015), 속눈 썹(Kwon \& Heo, 2019), 댄스 스포츠(Kim et al., 2013), 무 용전공 대학생(Kim \& Han, 2009)을 대상으로 한 연구에서와 같이 긍정적 이미지효과가 자기효능감 향상에 영향을 미친 것 으로 나타났다. 이 같은 결과로 자신에게 맞고 개인이 필요로 하는 이미지를 인지하고 형성을 하는 것이 중요하며, 자신의 이 미지 형성이 어렵다면 전문기관의 컨설팅을 권한다. 본 연구는 여성의 이미지에 대한 인식과 헤어 이미지 연출이 자기효능감 에 미치는 여향을 분석하여 적합한 이미지 선택 및 연출에 있어 서 지표가 될 수 있는 기초자료로 사용됨에 의의가 있다.

\section{Author's contribution}

MSH designed, performed experiments, analyzed data, and wrote the manuscript. YSK supervised project and all figures are created by the author and the coauthors. All authors read and approved the final manuscript.

\section{Author details}

Man-Suk Han (Graduate student), Department of Cosmetics Engineering, Konkuk University, 120 Neungdong-ro, Gwangjin-gu, Seoul 05029, Korea; Young-Sam Kim (Professor), Department of Image Industry, Graduate School of Engineering, Konkuk University, 120 Neungdong-ro, Gwangjin-gu, Seoul 05029, Korea. 


\section{References}

Cha SJ. Effects of physical images of dance majors on selfefficacy and interpersonal relation. Journal of Korean Dance, 33: 361-392, 2015.

Feingold A. Good-looking people are not what we think. Psychological Bulletin, 111: 340-341, 1992.

Hamermesh DS, Biddle JE. Beauty and the labor market. The American Economic Review, 84: 1174-1194, 1994.

Hassin R, Trope Y. Facing faces: studies on the cognitive aspects of physiognomy. Journal of Personality and Social Psychology, 78: 837-852, 2000.

Hong HR, Kim YI. The preferred fashion style and self-image that Korean career women's seek according to daily situations. Journal of the Korean Society of Beauty Costume, 66: 50-68, 2016.

Jin HY, Kim JY. A survey on the necessity and awareness of image making education. Journal of the Korean Society of Beauty Cultural Arts, 2: 3-13, 2013.

Kaiser SB. The social psychology of clothing: symbolic appearances in context (2nd ed.). Macmillan Publishing Co., New York, pp100-110, 1990.

Kim JH, Choi BY. Mediating effect of self-efficacy in the relationship between college students' body image and social anxiety. Journal of Youth Welfare, 17: 135-16, 2015.
Kim JY, Yoon IA, Joo HC. The structural relationships among body image, self-efficacy and dance flow of dance sport players. Journal of Coaching Development, 15: 107-117, 2013.

Kim JY. Convergence of facial image efficacy on job satisfaction of SME workers. Journal of Convergence for Information Technology, 8: 227-232, 2018.

Kim JY. Convergence of the image of the professor in human resources of small and medium enterprises to self image: mediating effect of voice image. Journal of Convergence for Information Technology, 7: 229-234, 2017.

Kim YM, Han HW. The influence of flow experience on self efficacy and satisfaction with dance activity of university students majoring in dance. Official Journal of Korean Society of Dance Science, 19: 1-18. 2009.

Moon IO, Lee GW, Jeong SH. Effect of image making programs on image making efficacy, positive thinking, self-esteem, and nursing professionalism in nursing students. Journal of Korean Academy of Nursing Administration, 21: 122-132, 2015.

Park MS. In the fusion era of jung, the relationship between college students' perfectionism and career indecision: focusing on mediation effect of career decision selfefficacy. Journal of Convergence for Information Technology, 8: 79-87, 2018. 


\section{국문초록}

\section{0-50대 여성의 이미지 인식과 헤어 이미지 연출에 따른 자기효능감}

한만석 ${ }^{1}$, 김영삼 ${ }^{2 *}$

${ }^{1}$ 건국대학교 화장품공학과, 서울, 한국

${ }^{2}$ 건국대학교 산업대학원 이미지산업학과, 서울, 한국

목적: 여성의이미지에 대한 인식과 헤어이미지 연출이 자기효능감에 미치는 영향을 분석하고자 한다. 방법: 경기도 지역에 거주하 는 20-50대 여성을 대상으로 자료를 수집하였고, 수집된 자료는 SPSS WIN 25.0 프로그램을 이용하여 분석 하였다. 분석기법으로 는 연구 참여자의 일반적 특성을 살펴보기 위해 빈도와 백분율을 구하였으며, 이미지에 대한 인식과 헤어이미지에 연출 따른 자기 효능감을 알아보기 위해 $t$-test 와 $\chi^{2}$-test 그리고 one-way ANOVA를 실시하였다. 결과: 여성들의 이미지 관심도와 이미지 변화 요인을 조사한 결과 일반적 특성별로는 큰 차이 없이 여성 대부분이 이미지 관리가 필요하며, 이미지 형성의 주요 원인은 언어, 헤 어스타일, 의복, 메이크업 순으로 나타났고, 이 중 헤어스타일의 변화시키는 주된 요인은 이미지 개선을 위한 것이며, 헤어이미지 연출이 잘 되었을 때 자기효능감이 높은 것으로 나타났다. 결론: 본 연구를 통해 적합한 이미지 선택 및 연출에 있어서 지표가 될 수 있는 기초 자료가 되며, 그 뿐만 아니라 개인의 자기효능감을 높일 수 있는 심리적 매개 요인으로써의 다양한 활용이 기대된다.

핵심어: 헤어이미지, 이미지인식도, 자기효능감, 헤어 연출, 이미지 변화요인

\section{참고문헌}

권태일, 허혜순. 속눈썹 미용실태에 따른 외모만족도와 자아존중감. 아시안뷰티화장품학술지, 17: 259-306, 2019. 김영미, 한혜원. 무용전공 대학생의 무용몰입 경험이 자기효능감과 무용활동만족에 미치는 영향. 한국무용과학학회지,

19: 1-18, 2009.

김정열. 중소기업 인적자원의 교수자이미지가 자아이미지에 미치는 융합연구: 교수자 음성 이미지의 매개효과. 융합정보 논문지, 7: 229-234, 2017.

김정열. 중소기업 직장인의 얼굴 이미지 효능감이 직무만족에 미치는 융합연구. 융합정보논문지, 8: 227-232, 2018. 김종학, 최보영. 대학생의 신체이미지와 사회불안과의 관계에서 자기효능감의 매개효과. 청소년복지연구, 17: 135-162, 2015.

김지영, 윤인애, 주형철. 댄스스포츠 선수들의 신체이미지와 자기효능감 및 댄스몰입의 구조적 관계. 코칭능력개발지, $15:$ 107-117, 2013.

문인오, 이경완, 정석희. 이미지메이킹 프로그램이 간호대학생의 이미지메이킹 효능감, 긍정적 사고, 자아존중감 및 간호 전문직관에 미치는 효과. 간호행정학회지, 21: 122-132, 2015.

박명선, 박종원. 융복합시대에 대학생들의 완벽주의와 진로미결정의 관계: 진로결정 자기효능감의 매개효과를 중심으로. 융합정보논문지, 8: 79-87, 2018.

조민희, 양진희. 얼굴형과 메이크업의 색상변화에 따른 이미지 지각에 관한 연구. 아시안뷰티화장품학술지, $15: 122-$ $131,2017$.

진형여, 김지연. 이미지 메이킹 교육의 인식도와 필요성에 관한 연구. 대한미용문화예술학회지, 2: 3-13, 2013. 차수정. 무용전공자의 신체이미지가 자기효능감 및 대인관계에 미치는 영향. 한국무용연구, 33: 361- 392, 2015. 홍혜림, 김영인. 한국 직장여성의 일상 상황별 추구하는 자기이미지와 선호 패션스타일. 복식, 66: 50-68, 2016. 


\section{中文摘要}

\section{0-50岁妇女的形象意识和通过毛发形象产生的自我效能感}

韓萬錫 ${ }^{1}$, 金永三 $^{2 *}$

建国大学化妆品工学科, 首尔, 韩国

2建国大学产业大学院影像产业学科, 首尔, 韩国

目的: 形象在社会和关系中起着重要的作用, 人们日益认识到, 管理自我形象对人际关系和社会生活的影响很 大。因此, 本研究旨在通过适当的形象和发型来提高自我效能并创造积极正面的形象。方法: 对京畿道的385名 妇女进行了问卷调查。使用SPSS WIN 25.0程序分析收集的数据, 进行频率和百分比, $x^{2}$ 检验, $t$ 检验和单向方 差分析。结果: 结果表明, 女性对形象的兴趣和一般特征中的形象变化因素没有显着差异, 并且大多数女性需要 管理形象。形成图像的主要原因是语言, 其次是发型, 服装和化妆, 其中, 改变发型的主要原因是改善形象。 很好地改善头发形象时, 总体平均分为3.82（满分5分）, 表明自我效能水平很高。结论: 这项研究将来可用于 选择和指导图像的索引的基本数据, 以及可以用作提高个人自我效能的心理中介。

关键词: 头发图像, 图像偏好, 自我效能感, 头发设计, 图像变化因素 